\title{
1996 Trainees' Forum
}

\author{
Peter Cornwall
}

\begin{abstract}
"Men at some time are masters of their fates: The fault, dear Brutus, is not in our stars. But in ourselves, that we are underlings" (Julius Caesar. Act I, Scene 2).
\end{abstract}

Stratford-upon-Avon was the perfect venue for the Winter Meeting of the Royal College of Psychiatrists in 1996. The Trainees' Forum was well attended by psychiatrists of all grades, despite being squeezed between the last session of the day and our first session of Shakespeare: Julius Caesar. The theme of the Forum was the desirability (or not) of a career in psychiatry in the modern NHS and the discussion was led by three senior psychiatrists with very different perspectives on the matter: Dr Mary-Jane Tacchi, Consultant Psychiatrist at Newcastle General Hospital; Dr Mike Harris, Medical Director of St Andrews Hospital, Northampton, and Professor Patricia Casey from Mater Hospital, Dublin.

Dr Tacchi spoke about her experiences of her first year as a consultant in the NHS, stressing the importance of being prepared for the pressures of consultant life. Dr Harris had recently moved from the NHS to the independent sector and described the differences between his last days as a consultant forensic psychiatrist at Mapperley Hospital in Nottingham to his first days as a medical director of a private psychiatric hospital. As a trainee, he had never imagined leaving NHS practice, but he did not regret his decision. Professor Casey reviewed the status of a career in academic psychiatry. She spoke of the excitement to be achieved through research, but she also recognised that pursuing an academic career demanded a degree of single-mindedness that was not to everyone's taste.

All the speakers emphasised getting the basics right from the beginning - for example, making sure your office is suitable (and even making sure you have an officel), and discussing with your secretary how your diary will be planned. Time planning is a very important issue with the multiple demands that are made on consultants, you must ensure that you make time for activities outside work. For many consultants it is easier to avoid taking a holiday than making the time to plan for being away from work. Delegation and time management are crucial skills.

Discussion from the floor focused on the preparation for the role of a consultant. Questions were asked as to whether current senior registrar training adequately equipped trainees for the pressures of consultant life. Dr Tacchi recommended that trainees make the most of opportunities in management training - through taking part in relevant activities while training and attending courses in management. The implications of the Calman changes to training were discussed at some length. How will the job of a consultant change if trainees are providing less by way of service commitment? How will trainees gain sufficient experience? Will there be two classes of consultants - those with and those without trainees working with them? Interest was expressed in alternative work models for senior doctors but it was unclear as to how changes could be made within the current structures of the NHS. Comments were made about the necessity of the profession (through the College) asserting itself to society in general and to the Government in particular, to promote the values of psychiatry and to protect those working in the profession. Those who spoke were realistic about the challenges of a career in psychiatry, but no-one expressed the view that they would rather have taken a different path. Like Cassius and Brutus, it is up to trainees to shape their own futures, though perhaps with a more positive outcome.

Peter L. Cornwall, Clinical Research Associate, Department of Psychiatry. University of Newcastle Upon Tyne and Collegiate Trainees Committee, Royal College of Psychiatrists 